\title{
Economía Comunitaria desde la Perspectiva Intercultural de Género para el Buen Vivir de los Pueblos "Otra Economía es Posible"
}

Víctor Ronald Zúniga Morales ${ }^{1}$

\section{Resumen}

Esta investigación ha analizado la experiencia de la Universidad de las Regiones Autónomas de la Costa Caribe Nicaragüense (URACCAN), el gobierno y la participación familiar en la economía comunitaria. Es una investigación cualitativa desde una perspectiva hermenéutica, se analizaron libros, artículos científicos, informes de congresos, artículos de prensa, políticas y normas institucionales.

Los resultados revelan que en América Latina las familias y pueblos mestizos, indígenas y afrodescendientes están buscando formas que les permita no sólo sobrevivir, sino vivir de manera digna y justa. La economía comunitaria es otro modelo civilizatorio, es una filosofía que hoy emerge con raíces ancestrales, fortalecida por las diversas prácticas socioeconómicas de familias, organizaciones, pueblos y que afirman que "Otra Economía es Posible". Por tanto, es necesario plantear algunos retos para potenciar la economía comunitaria y ser el cimiento del nuevo paradigma que es la Economía Social Solidaria.

Palabras clave: economía comunitaria; economía social solidaria; políticas públicas; participación.

\section{Summary}

This research has analyzed the experience of the University of the Autonomous Regions of the Nicaraguan Caribbean Coast, the government and family participation in terms of the community economy. It was a qualitative research from a hermeneutical perspective, books, scientific articles, congress reports, press articles, policies and institutional norms were analyzed. The results revealed that in Latin America, mestizo, indigenous and afro-descendant families and peoples are looking for ways that allow them not only to survive, but to live in a dignified and just system; even if it is not strengthened, it is the loss of the community economy by conventional economic systems. The community economy is another civilizatory model, it is a philosophy that today emerges with ancestral roots, strengthened by the diverse

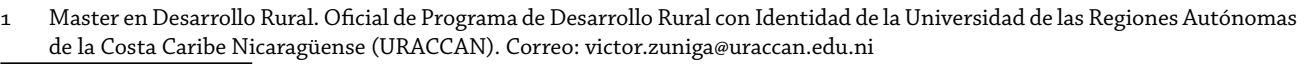

Recibido: 23/10/2017 Aprobado: 23/11/2017 
socioeconomic practices of families, organizations and peoples and that affirm that "Another Economy is Possible". Therefore, it is necessary to pose some challenges to strengthen the community economy and be the foundation of the new paradigm that is the Social Solidarity Economy.

Key Words: community economy; social solidarity economy; public politics; participation.

\section{Introducción}

El concepto de Economía Social y Solidaria (ESS), tiene cuerpo en las últimas dos décadas, fruto de los debates que se están suscitando en torno suyo y de nuevas prácticas económicas extendidas cada vez con más fuerza, en numerosas partes del planeta. A nivel mundial, los gobiernos reconocen cada vez más la importancia de la ESS y su papel como un mecanismo tanto para la reducción de la pobreza como para la generación de empleo, puesto que el sistema tradicional ha generado sólo una serie de crisis en la sociedad.

Este tema toma relevancia en América Latina, cuando vemos que el empleo informal asciende a 50\%, con una tendencia preocupante, (Banco Mundial, 2014) de los 632 millones de habitantes en América Latina, un 20\% corresponde población rural y el $50 \%$ representa a la población económicamente activa de los cuales el $42 \%$ son mujeres, (CELADE, 2016) y cuenta con 665 Pueblos Indígenas que representan casi el 7\%, de la población en general (UNICEF, 2009).

En América Latina y el Caribe, Nicaragua es uno de los más pobres y el que más sufrió en los años setenta y ochenta debido a dictaduras, desastres naturales, conflictos y crisis económicas; cuenta con una población de 6.2 millones de habitantes, una población económicamente activa de 3.2 millones, un Producto Interno Bruto (PIB) de 13.2 mil millones de dólares en el 2016 y un territorio de 130, $000 \mathrm{Km}^{2}$, se trata de un país y de una economía pequeña (BCN, 2016). De acuerdo al Atlas Sociolingüístico de Pueblos Indígenas en América Latina, el 8.6\% de la población total son indígenas. Con un PIB per cápita de apenas 2,090.8 dólares de los Estados Unidos. De la población económicamente activa, el 75 por ciento forma parte de la denominada economía informal (BCN, 2015)., Otras fuentes afirman que es del $73.5 \%$ (FIDEG, 2012), habiendo pocas diferencias. Según la encuesta de hogares para medir la pobreza en Nicaragua realizada por el Fideg en el 2012, el 19.9\% de la población ejerce un trabajo no remunerado, mientras que el $32.7 \%$ labora por cuenta propia y de estos últimos, el 60\% realiza sus actividades principalmente dentro de la vivienda o la finca. Según datos oficiales, donde más se acentúa el trabajo informal es en el sector rural, porque allí el 86\% labora en esa área de la economía. En el año 2005, casi la mitad de la población en Nicaraguafue clasificada como pobre 48\% (FIDEG, 2010), 
esta cifra disminuyó al 44\% (FIDEG, 2012) y se reporta un último dato del $29.6 \%$ por parte del gobierno (INIDE, 2015).

La constitución política reconoce a Nicaragua como un país multicultural, multilingüe, y, multiétnico, puesto que, en este país, los pueblos indígenas presentan dos historias distintas. En primer lugar, los Pueblos del Pacífico Sur de origen mesoamericano, fueron sometidos bajo el dominio de las políticas coloniales y en consecuencia fueron desarticulados de sus culturas y territorios. Desde hace unas dos décadas se viene generando un proceso de visibilización de los pueblos mediante la conformación del Consejo de Pueblos Indígenas del Pacífico, Centro y Norte de Nicaragua (PCN) que aglutina a "22 pueblos indígenas descendientes de culturas cacaopera, chorotega, nahoa y xiu", desde este espacio se ha luchado para que el Estado apruebe una Ley de Autonomía para estos pueblos (APRODIN, 2011). Por su parte, la Costa Caribe presentan una historia distinta, fue colonizada por ingleses, representa el $48 \%$ del territorio nacional y conviven pueblos indígenas: miskitus, sumus mayangnas, ulwas y ramas, asimismo mestizos y afrodescendientes: creoles y garífunas. Cada pueblo mantiene su propia lengua, cosmovisión, memorias colectivas, organización social, justicia consuetudinaria, espiritualidad, tierra y territorio, diferenciándose entre sí y del resto de la población, demostrando una gran diversidad sociocultural (Hooker, 2017).

Las Regiones Autónomas de la Costa Caribe Nicaragüense, cuentan con la Ley 28 de Estatuto de Autonomía, en ella se reconoce el pluralismo étnico, el respeto de la libre autodeterminación de los pueblos, el reconocimiento de la existencia de los pueblos indígenas y sus derechos y especialmente, el derecho a mantener y desarrollar su Autonomía Regional. La ley garantiza que los pueblos gocen de su identidad y cultura, tener sus propias formas de organización social y administrar sus asuntos locales, así como mantener las formas comunales de propiedad de sus tierras. A partir de ahí se han dado significativos avances como la creación de dos regiones autónomas con sus respectivas autoridades, asimismo la creación de la Universidad Comunitaria Intercultural URACCAN ${ }^{2}$.

En Nicaragua, el término Economía Social Solidaria es incipiente al igual que hablar de Economía Comunitaria, se utilizan términos como "Economía Popular". Este sector ha visto una mayor atención de parte del gobierno actual ${ }^{3}$. En el país, existen tres economías, la economía transnacional, empresa privada nacional y la economía de base (popular, social, solidaria, indígena, comunitaria). Los datos presentados nos afirman que la Economía Popular es la más grande en el país, basada en la unidad económica familiar donde la mujer es el principal sostén y al mismo tiempo ocupa el lugar más desventajoso (discriminación, encargada de la familia, reproducción social sin recompensa y trabajadora).

2 En el 2002, los Gobiernos Regionales Autónomos declararon a la Universidad de las Regiones Autónomas de la Costa Caribe (URACCAN), patrimonio de los Pueblos Indígenas.

Gobierno de Reconstrucción y Unidad Nacional implementado por el Frente Sandinista de Liberación Nacional. 


\section{CIENCIAS SOCIALES}

La Economía Popular es la suma de familias empobrecidas o de trabajadoresproductores, individuales o aislados y colectivos, que no están económicamente organizados, aportan más del 50\% del Producto Interno Bruto, produce el 90\% de la alimentación (asegurando la soberanía y seguridad alimentaria del país), tiene el 70\% de la tierra, controla el 60\% de los productos y servicios de exportación, genera más del 80\% del empleo, la mayor parte de los servicios, como el transporte y el comercio, provee el 95\% de las remesas familiares (PASTRAN, 2015). Las remesas en el 2016, representaron el $56.4 \%$ del valor de las exportaciones de mercancías del país. (BCN, 2016).

En fin, vemos que la economía popular es la más empobrecida porque está situada en el proceso inmediato de producción, es decir, no accede a los eslabones superiores de la cadena de valor (industria y comercio exterior), es una economía explotada a través del mercado, marginada social y políticamente. Sin embargo, esta tiene iniciativa y una dinámica que es cada vez es más visible debido al aumento del desempleo y la pobreza.

Ante esta situación en Nicaragua han surgido algunos Movimientos Sociales que han girado alrededor de la economía popular-familiar y su agenda es la misma que la del resto de América Latina, luchan contra el neoliberalismo, la privatización, por el derecho y acceso a la tierra, el empleo, crédito, apoyo del Estado con la asistencia técnica, la capacitación, la promoción de la asociatividad, la autogestión, autodeterminación,,presionan por políticas públicas, programas y leyes a favor de sus intereses, por su participación ciudadana, política, social, cultural y económica. La existencia de nuevos y diferentes movimientos sociales como los movimientos estudiantiles, consumidores, mujeres, pobladores, ecologistas, pueblos indígenas, afrodescendientes y comunidades étnicas, entre otros, han contribuido a desarrollar la identidad política de la economía popular ya que la mayoría se identifican con los principios de justicia, equidad social, auto determinación de los territorios y respeto a la Madre Tierra.

En el contexto actual se puede decir que hay avances y condiciones para progresar en la consolidación de la Economía Social Solidaria a partir de la Economía Comunitaria. Este artículo, responde de forma empírica a preguntas referidas a ¿Qué se entiende por Economía Social Solidaria?; ¿Qué es la Economía Comunitaria y cuál es su importancia? ¿Cuáles son las políticas que existen en el país (nacional y local) en ESS? ¿En qué consisten los aciertos, las limitaciones y la participación de las y los actores de la ESS y cómo éstos se han dado?; Asimismo, poder determinar si: ¿Existe alguna experiencia desde URACCAN y por parte del Gobierno?,¿Cuáles serían los principales retos para consolidar la Economía Social Solidaria en el país? 


\section{Materiales y métodos}

El presente estudio se enmarca en el paradigma cualitativo porque es una actividad sistemática orientada a la comprensión en profundidad de fenómenos sociales, a la transformación de prácticas y escenarios sociales, a la toma de decisiones y también hacia el descubrimiento y desarrollo de un cuerpo organizado de conocimiento. Desde esta perspectiva, Hernández et al (2010), explican que en el paradigma cualitativo el enfoque o diseño "es el abordaje general que utilizará el investigador en el proceso de investigación" (p. 492). En este sentido, esta investigación tiene un enfoque hermenéutico, porque se interpretaron los significados de textos y acciones en el proceso de la economía comunitaria.

Por tales razones, se utilizó como método el análisis de contenido de los textos, el cual ayudó a describir los documentos en sus partes esenciales. Para ello, se empleó la técnica de revisión de documentos, donde nos centramos en los argumentos, razones, propósitos y los significados que los mismos presentan sobre la economía comunitaria. Por consiguiente, se construyó una guía de revisión documental como instrumento, que permitió analizar los textos de libros, artículos científicos, artículos de prensa, leyes, políticas y normas institucionales.

\section{Resultados y discusión}

\section{¿Qué se entiende por Economía Social Solidaria?}

La Economía Social Solidaria es un fenómeno complejo con diferentes facetas y corrientes: económicas, sociales, políticas, culturales y ambientales, que constituyen un Proyecto Ético de Vida. La ESS, en cuanto a concepto debe catalogarse como algo nuevo que en los últimos años se ha venido construyendo producto de aprendizajes de experiencias, estudios, grupos sociales, conocimiento ancestral de los pueblos indígenas entre otros.

El marco conceptual más consistente es el propuesto por Razeto $(1984)^{4}$, según el cual la economía solidaria se caracteriza por una orientación fuertemente crítica y decididamente transformadora respecto de las grandes estructuras y los modos de organización y de acción que caracterizan la economía contemporánea. Desde este punto de vista hace énfasis en la solidaridad, la cooperación y la reciprocidad como fuerzas económicas efectivamente existentes en la realidad social y con posibilidades de crear nuevas formas de hacer economía socialmente eficaz y eficiente.

4 Luis Razeto (1984) desarrolla el concepto de economía de la solidaridad en su trilogía Economía de la Solidaridad y Mercado Democrático. 


\section{CIENCIAS SOCIALES}

En la producción el elemento definitorio es la preeminencia del trabajo sobre el capital; en la distribución la lógica de la reciprocidad, redistribución y cooperación determinan la circulación y la asignación de recursos productivos, además del valor monetario y en cuanto al consumo enfatiza el cambio en la cultura hacia una visión más integral de la satisfacción de las necesidades humanas, tomando en cuenta la austeridad y simplicidad, en equilibrio entre el consumo y cuidado del medio natural, por intercambios justos.

Otra fuente de construcción de este pensamiento se encuentra en Brasil ${ }^{5}$, para ellos, la Economía Solidaria supone un proyecto de transformación social que procura construir una economía alternativa a las prácticas dominantes y al capitalismo imperante; rescatan la autogestión y el asociacionismo en las clases populares. Hoy en día han surgido algunos emprendimientos de Economía Social y Solidaria en las cuales existen coincidencias y similitudes, pero también diferencias que no profundizaremos en este artículo.

La Economía Solidaria, está demostrando muchísimo más dinamismo y creatividad como catalizador de cambio social, como son: sus vinculaciones con la economía feminista y su objeto de estudio de la economía; los debates y análisis sobre los sistemas de intercambio basados en el trueque o los sistemas sustentados en monedas locales; la incorporación de la esfera de la distribución a través del comercio justo y la articulación de mercados sociales; la creciente importancia otorgada a las reflexiones y las experiencias de consumo responsable; o la ampliación del ámbito financiero de la economía social hacia el campo de las finanzas éticas y solidarias.

En Nicaragua, aún cuando se habla poco de esta idea de Economía Social Solidaria, hay muchos ejemplos. Para la Universidad de las Regiones Autónomas de la Costa Caribe Nicaragüense (URACCAN) desde que abrió sus puertas en enero de 1995 comenzó a promover y aportar al proceso autonómico a través de la formación de hombres y mujeres, creación y recreación de conocimientos y acompañamiento de procesos de extensión social comunitaria como el Modelo de Salud Autonómico Regional, Sistema Educativo Autonómico Regional, la promoción de la Economía Comunitaria Intercultural entre otros.

En el contexto actual a dos años de haber finalizado el período de los Objetivos de Desarrollo del Milenio y haber iniciado uno nuevo período con nuevos objetivos ahora de Desarrollo Sostenible, desde la URACCAN decimos que no basta con las tres dimensiones del Desarrollo Sostenible basado en lo Social, Ambiental y Económico, también es importante la dimensión cultural, pilar de desarrollo con identidad para el Buen Vivir de los Pueblos desde su comunidad. En el marco del derecho a la libre determinación, el concepto de desarrollo sostenible basado en la diversidad cultural 
asegurará los medios de vida en una relación respetuosa con el territorio y complementaria con la naturaleza y sus seres vivos. El desarrollo desde la cultura y la identidad, respetando la tradición y la espiritualidad con visión de futuro, se caracteriza por construir y asegurar derechos colectivos, autogobierno y gobernanza de tierras, territorios y conocimientos ancestrales.

La URACCAN, es una apuesta a un cambio de paradigma del concepto convencional de Universidad sustentados en los elementos del modelo de Universidad Comunitaria Intercultural. Estos son: a) La Importancia de la comunidad, los sabios, ancianos y autoridades no tradicionales; b) Búsqueda de nuevos paradigmas en los enfoques metodológicos y de generación de conocimientos; c) La Espiritualidad indígena (miskitu, rama, mayangna), afrodescendientes (creoles y garífunas) y mestizas, d) La Interculturalidad, e) El papel central de la investigación e innovación, f) Perspectiva intercultural de género, g) La articulación entre teoría y práctica, h) El acompañamiento y i) La cultura.

En este sentido, la URACCAN promueve la Economía Comunitaria Intercultural con bondades que puede ser referente de la Economía Social Solidaria, desde la concepción del papel de los seres humanos indígenas, afrodescendientes y mestizos en el planeta, hasta los principios de reciprocidad y trabajo comunitario la Economía Comunitaria, en el horizonte del Buen Vivir, plantea un nuevo paradigma que se explica, articula y se fundamenta desde la comunidad, como sistema de organización de vida. La comunidad se comprende como "la unidad y estructura de vida", es decir, el ser humano es sólo una parte de esta unidad; animales, insectos, plantas, montañas, el aire, el agua, el sol, incluso lo que no se ve, nuestros ancestros y otros seres, son parte de la comunidad. Todo vive y todo es importante para el equilibrio y la armonía de la vida (Jubeto, Guridi, y Villa, 2014).

En los pueblos indígenas y afrodescendientes existe y perdura una concepción más amplia que se tiene de la comunidad. Por ejemplo, la comunidad miskita, desde la espiritualidad se entiende que existe interrelación entre todo lo que existe en el universo, de ahí la integralidad de la cosmovisión indígena, la comunidad es entendida como un espacio en el que es posible la consecución del buen vivir de todos, trabajando en "Pana pana" (en cooperación), "Taika nani daknika" (círculo de familiares), "Bakahnu" (juntos) "Yui pí" (compartiendo), "ta baiki" (ayudando), "laman lakara" (en paz), "kupia kumi lakara" (viviendo en armonía). (Cox, 2016)

Para URACCAN, trabajar la Economía Comunitaria, ha significado considerar algunos elementos, principios, valores, dimensiones, pilares y gestión comunitaria, (Zúniga, 2010). Los principales elementos que se consideran son: la comunidad, la espiritualidad, la cosmovisión y la perspectiva intercultural de género (Zúniga 2013). En la comunidad, el ser humano no es el único ser, ya que todo tiene vida, por ejemplo, no hay lugar para la palabra recursos, ya que si todo vive lo que existe son seres y no 


\section{CIENCIAS SOCIALES}

objetos, bajo este precepto no se pretende dominar nada, tampoco cabe la idea de explotación de nada ni de nadie, el beneficio no sólo es del ser humano es de todos; todo está en una relación complementaria, en un perfecto equilibrio. Todo está conectado, relacionado e independiente (económica, educativa, jurídica, políticamente y así mismo la agricultura). En la espiritualidad y cosmovisión indígena, los recursos naturales distan mucho de ser una posesión económica. El territorio es la base para desarrollar la vida cultural, así como el modelo o sistema jurídico, político, social y económico, considerando la espiritualidad, la cosmovisión y cosmogonía de cada pueblo. La Perspectiva Intercultural de Género, es un enfoque teórico-práctico en construcción permanente, que aborda las brechas históricas de desigualdades entre mujeres y hombres, en programas, proyectos y procesos de acompañamiento de la URACCAN hacia las comunidades se apuesta a superar las múltiples formas de opresión y relaciones de subordinación, con énfasis en las de género, como una exigencia de derechos, entendiendo los cambios en las situaciones y posiciones hegemónicas de género, como exigencias para ejercicio pleno de la ciudadanía intercultural por la equidad, en pro de la consecución de un desarrollo con identidad que reconozca la cosmovisión, sueños y aspiraciones diferentes de mujeres y hombres a lo interno de sus pueblos, y entre los mismos. Los Principios son: sueños y aspiraciones, participación voluntaria, amor individual-familiar-comunitaria, respeto-equilibrio-armonía, diálogo de saberes y haceres, decisiones colectivas, reciprocidad, bien común, perspectiva intercultural de género y valorar la vida). Los Valores son: responsabilidad, honestidad, transparencia). Dimensiones (políticas, ambientales, económica y cultural. Los pilares son: Organización, producción respetuosa con el medio ambiente y madre tierra, distribución, finanzas éticas y moneda comunitaria. En la gestión comunitarias: colectividad, autogestión y autodeterminación, solidaridad, propiedad y racionalidad económica.

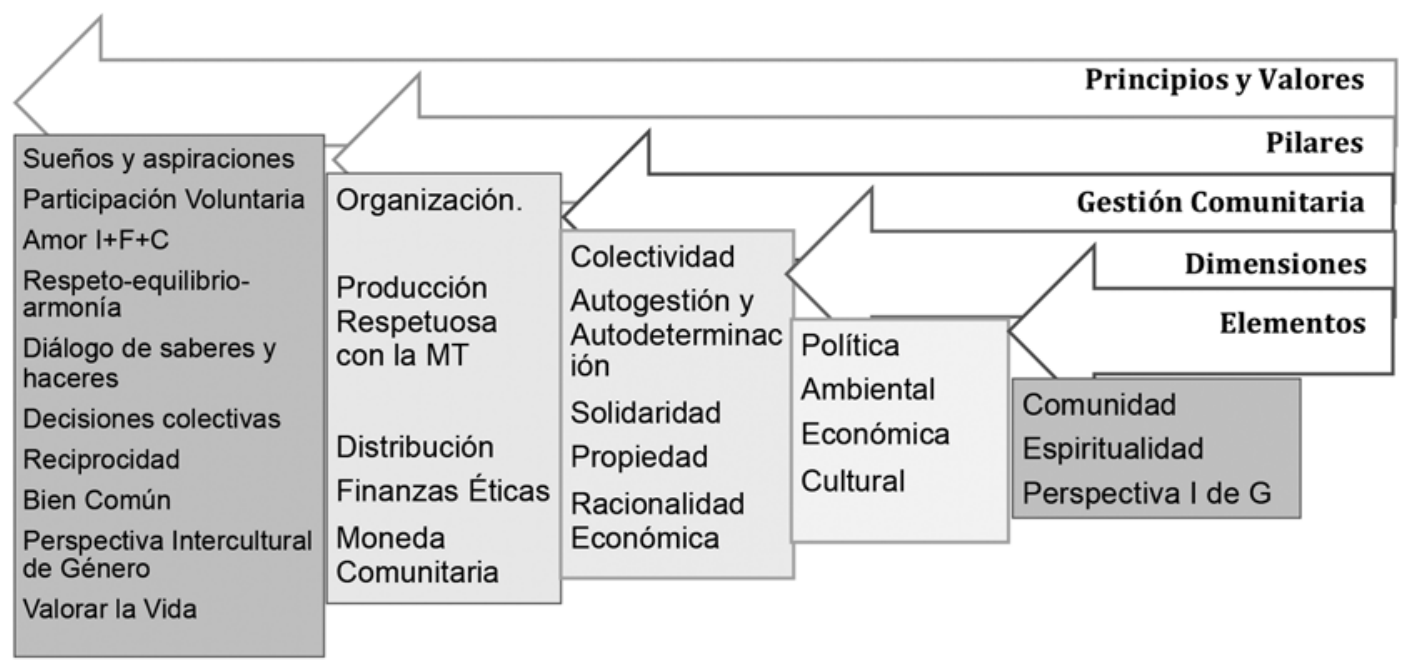

Figura 1: Esquema general elementos de la "Economía Comunitaria Intercultural" 
Las prácticas comunitarias de los pueblos ofrecen ejemplos de aplicación de la lógica de la economía comunitaria bases para las políticas públicas. Desde la comunidad se dan relaciones económicas de complementariedad y reciprocidad con la vida, la madre tierra, la comunidad y la familia. Toda relación económica es vista para preservar la vida y no con fines de generar capital y enmarcarse no sólo en leyes económicas sino también en leyes naturales. Bajo el principio del equilibrio, la complementariedad genera la distribución y la redistribución, según la necesidad del momento. En la comunidad, cada familia tiene el "derecho de relación" con la Madre Tierra de acuerdo con su número de miembros. En la dinámica de la complementariedad, los miembros de la comunidad reciben y aportan de acuerdo con sus necesidades y responsabilidades, estos y otros elementos es lo que lo diferencia a la Economía Comunitaria Intercultural de la Economía Convencional.

Tabla 1: Diferencias entre Economía Convencional y Comunitaria Intercultural

\begin{tabular}{|c|c|c|}
\hline Economía Convencional & & Economía Comunitaria Intercultural \\
\hline $\begin{array}{l}\text { - Individualista. } \\
\text { - Antropocéntrica. } \\
\text { - Desintegrada de la vida. } \\
\text { - Homogeneizadora. } \\
\text { - Jerárquica. } \\
\text { - Competitiva. } \\
\text { - Orientada al consumo y al capital } \\
\text { - Reglas: lucro y competencia. } \\
\text { - Anti-valores: avidez, envidia, desconfianza, } \\
\text { irresponsabilidad, egoísmo. }\end{array}$ & Vrs. & $\begin{array}{l}\text { - Colectiva. } \\
\text { - Todo vive y todo es importante para el } \\
\text { equilibrio y la armonía de la vida. } \\
\text { - Respeto a la vida. } \\
\text { - Equilibrio y armonía. } \\
\text { - Horizontal. } \\
\text { - Reglas: Solidaridad, bien común, recipro- } \\
\text { cidad, redistribución, racionalidad. } \\
\text { - Valores humanos: honestidad, aprecio, } \\
\text { confianza, responsabilidad, solidaridad. }\end{array}$ \\
\hline
\end{tabular}

En fin, la Economía Comunitaria Intercultural, puede aportar a un paradigma diferente, es otro modelo civilizatorio que se construye desde los saberes, conocimiento y prácticas de los pueblos considerando sus entornos históricos, culturales, ambientales y sus organizaciones, es una filosofía y práctica que hoy emerge con raíces ancestrales, fortalecido por las diversas prácticas socioeconómicas de familias, organizaciones y pueblos. "Otra economía es posible". Cambiemos las reglas que rigen el comportamiento económico en los mercados como el afán de lucro y la competencia que genera antivalores inconstitucionales, por un sistema donde las reglas sean la cooperación, equilibrio, armonía, solidaridad y el bien común que propician los valores humanos constitucionales.

Por tanto, la Economía Social Solidaria (ESS), puede ser una forma de convivencia entre las personas y la naturaleza que satisface las necesidades humanas y garantiza el sostenimiento de la vida, con una mirada integral, mediante la fuerza de la organización, aplicando los conocimientos, saberes y prácticas ancestrales para transformar la sociedad y construir una cultura de paz sin diferencias culturales, étnicas, sexo, geográficos u otras. 
En la práctica la Economía Social Solidaria (ESS), no debe ser una dimensión económica limitada, para impulsar procesos complementarios, articulados para generar un verdadero cambio, hay que considerar diversas dimensiones optimizando en cada espacio las potencialidades disponibles y obteniendo efectos multiplicadores en todas las áreas estas dimensiones son: la dimensión política, la dimensión ambiental, la dimensión económica y la dimensión cultural.

\section{Instrumentos políticos en el país que promueven la ESS}

El retorno al poder en el 2007 del Frente Sandinista de Liberación Nacional (FSLN) ha significado el establecimiento de un régimen híbrido, con aspectos desarrollistas y populistas que oficialmente apoyan a la ESS. Sin embargo, dicho apoyo tiene lugar en un contexto de continuas limitaciones del mercado asociadas con la austeridad fiscal, un aparato estatal debilitado y tratados regionales de "libre comercio". A diecisiete años después de su primera derrota electoral, el FSLN regresó al poder mediante unas elecciones democráticas. Con el lema "cristiano, socialista y solidario, el gobierno declaró su apoyo hacia una economía social y solidaria, aunque usando términos como economía popular y asociativa. A diez años, no hay duda que la ESS ha tenido importantes avances a través de programas y acciones que se implementan a nivel local y territorial con sus debilidades, pero con evidencias del diseño e implementación de distintas tipologías innovadoras de acciones de ESS.

Una tendencia en muchos países en vías en desarrollo es que las políticas sociales se orientan hacia los sectores más pobres a través de programas insignia de gobiernos. Normalmente esto ocurre al crear programas de transferencia monetaria condicionada que asignan un monto de dinero a los hogares -casi siempre a las madres-. Si bien el Gobierno de Nicaragua también ha utilizado programas de alto perfil como parte de su estrategia de reducción de la pobreza, la naturaleza de estas iniciativas ha sido diferente. En lugar de ser de tipo asistencialista (es decir, que fortalezca el acceso de personas individuales a los servicios sociales y la asistencia), tienen como blanco el fortalecimiento directo de la capacidad productiva de la mujer y su empoderamiento.

Un estudio realizado en Nicaragua por el Centro Internacional de Formación de la OIT en el 2014, identificó 21 programas que favorecen la Economía Popular y Asociativa, cuatro de ellos son ejecutados actualmente por el Ministerio de Economía Familiar, Comunitaria, Cooperativa y Asociativa (MEFCA), ligados al acceso al crédito y otros recursos financieros. Programa Usura Cero ejecutado por el Banco Produzcamos, de igual manera ligado al acceso al crédito y otros recursos. Programa Amor, ejecutado por el Ministerio de la Familia (MIFAM), ocho programas del Ministerio del Trabajo $y$, por último, seis programas sobre formación profesional bajo el tutelaje del Instituto Nacional Tecnológico (INATEC). A continuación, se presenta el detalle de los Programas identificados. 
Tabla 2: Principales Políticas y Programas de Gobierno

\begin{tabular}{|c|c|}
\hline Programa o Política & Objetivo \\
\hline $\begin{array}{l}\text { Programa producti- } \\
\text { vo Alimentario (PPA) } \\
\text { Hambre Cero }\end{array}$ & $\begin{array}{l}\text { El objetivo de la política de seguridad y soberanía alimentaria es la erradicación } \\
\text { del hambre de la población más pobre, priorizando a la niñez. Para cumplir este } \\
\text { objetivo se promueve la generación de capacidades, así como la capitalización de } \\
\text { las familias productoras empobrecidas. }\end{array}$ \\
\hline $\begin{array}{l}\text { Desarrollo del sector } \\
\text { lácteo en los departa- } \\
\text { mentos de Chontales, } \\
\text { Río San Juan y RACCS } \\
\text { (PRODERUL) }\end{array}$ & $\begin{array}{l}\text { Incrementar el aporte del sector ganadero/lechero y de la agroindustria láctea a } \\
\text { la reducción de la pobreza de los productores rurales en los municipios de Santo } \\
\text { Tomás, Villa Sandino, Muelle de los Bueyes, El Rama, San Miguelito y San Carlos. } \\
\text { Protagonistas directos: productores de leche organizados en asociaciones o coo- } \\
\text { perativas, organizaciones momentáneas en vías de ser cooperativas y grupos de } \\
\text { mujeres organizadas en el Programa del Bono Productivo. }\end{array}$ \\
\hline $\begin{array}{l}\text { Plan especial de produc- } \\
\text { ción de granos básicos } \\
\text { Cristiano, Socialista y } \\
\text { Solidario (CRISSOL) }\end{array}$ & $\begin{array}{l}\text { Restituir los derechos de las familias productoras empobrecidas del país, facilitán- } \\
\text { doles recursos financieros para la compra de semillas de granos como, frijol, maíz, } \\
\text { arroz, sorgo tortillero y herramientas de trabajo, para garantizar las siembras en } \\
\text { sus parcelas. }\end{array}$ \\
\hline $\begin{array}{l}\text { Programa Centro } \\
\text { Regional de Promoción } \\
\text { de la MIPYME } \\
\text { (CENPROMIPYME) }\end{array}$ & $\begin{array}{l}\text { La formación a mujeres empresarias emprendedoras en temas como las } \\
\text { Tecnologías de Información y Comunicación (TIC), la garantía de un capital de } \\
\text { semilla para el desarrollo de emprendimientos y la realización de un monitoreo } \\
\text { evaluativo de las MIPYMES; son parte de las acciones a desarrollar en capacidad y } \\
\text { eficiencia. Es un programa con presencia nacional que tiene como protagonis- } \\
\text { tas } 300 \text { MIPYMES de Nicaragua. Tiene como objetivo mejorar los instrumentos de } \\
\text { apoyo al sector mediante la creación de un sistema de información regional, con } \\
\text { criterios homologados y comparables. }\end{array}$ \\
\hline Usura Cero & $\begin{array}{l}\text { El crecimiento económico familiar de las mujeres a través del otorgamiento de } \\
\text { microcrédito con bajas tasas de interés, para el impulso de nuevos negocios o el } \\
\text { fortalecimiento de los ya existentes. }\end{array}$ \\
\hline $\begin{array}{l}\text { Amor (programa urbano } \\
\text { de atención a la niñez en } \\
\text { extrema pobreza) }\end{array}$ & $\begin{array}{l}\text { Crear y habilitar Centros de Desarrollo Infantil para el cuido profesional de las hijas } \\
\text { y los hijos de las madres que trabajan. La atención integral de las hijas y los hijos } \\
\text { de las madres trabajadoras es una prioridad fundamental. Esta atención se garan- } \\
\text { tizará a través de la ampliación de los Centros de Desarrollo Infantil en las zonas } \\
\text { urbanas y la extensión de centros infantiles comunitarios a las zonas rurales. }\end{array}$ \\
\hline $\begin{array}{l}\text { Formación a colectivos } \\
\text { de mujeres socias del } \\
\text { PPA Hambre Cero }\end{array}$ & $\begin{array}{l}\text { Crear oportunidades para que las mujeres, organizadas en grupos solidarios, pue- } \\
\text { dan beneficiarse de préstamos para mejorar sus pequeños negocios o emprender } \\
\text { uno nuevo. Capacitaciones en el cuido de aves, ganado mayor y menor, género, } \\
\text { autoestima etcétera. }\end{array}$ \\
\hline $\begin{array}{l}\text { Formación profesional a } \\
\text { mujeres }\end{array}$ & $\begin{array}{l}\text { El INATEC capacita a las mujeres donde indican los Consejos del Poder Ciudadano } \\
\text { (CPC), para facilitarles el acceso al crédito. Busca crear oportunidades para que } \\
\text { las mujeres, organizadas en grupos solidarios, puedan beneficiarse de préstamos } \\
\text { para mejorar sus pequeños negocios o logren emprender uno nuevo, y capacitar } \\
\text { a mujeres beneficiarias del programa para el buen manejo de sus negocios. }\end{array}$ \\
\hline
\end{tabular}




\section{CIENCIAS SOCIALES}

\section{Programa o Política}

Formación profesional a personas de las zonas rurales y semi-rurales

\section{Objetivo}

Capacitar a través de Cursos Móviles a la población de los sectores semiurbano y rural, en especialidades u oficios de acuerdo a las necesidades de desarrollo local. Capacitar a grupos de participantes en su lugar de origen en oficios que les permitan mejorar sus ingresos.

\section{Programa o Política}

Formación profesional a jóvenes

\section{Objetivo}

Brinda a los jóvenes de ambos sexos las herramientas técnicas necesarias para el empleo o autoempleo. Capacitar a jóvenes en especialidades de los tres sectores de la economía de las modalidades de formación, habilitación y aprendizaje técnico.

Formación profesional a jóvenes en distintas especialidades

Preparar a jóvenes de ambos sexos para desempeñarse en ocupaciones técnicas de nivel medio, en los sectores Industrial, Comercial y Agropecuario. Egresar a jóvenes con conocimientos técnicos en los niveles técnico básico, técnico medio y bachillerato técnico.

Programa de intermediación laboral

Gestionar de forma integral los programas de intermediación y colocación de demandantes de empleo en el mercado de trabajo, dotando a las personas desempleadas de herramientas básicas para búsqueda de trabajo, a través de talleres de orientación laboral. Gestión y facilitación del proceso de tramitación de empleo; intermediación para la inserción laboral exitosa de las personas inscritas en el Servicio Público de Empleo (SEPEM).

Curso de habilitación profesional. Programa de Inserción Laboral Inicial

Creación de empleos plenos y productivos para jóvenes del campo y la ciudad

Fomento y generación de trabajo colectivo de jóvenes del campo

Fomento y desarrollo del autoempleo en los departamentos con mayor índice de flujos migratorios

Proyecto de mejora al empleo de madres de niños/as Pica Piedras
Habilitar en técnicas funcionales gerenciales a jóvenes recién egresados/as de las universidades en elaboración de Planes Estratégicos de Mercadeo y Ventas e insertarlos/las empresas de los sectores de Servicio y Comercio.

Potenciar las capacidades, habilidades y destrezas de 72 jóvenes, entre mujeres y hombres de 20 y 30 años de edad, en los municipios de Jinotega, Masaya, por medio del desarrollo de cursos técnicos a cargo del INATEC para, posteriormente, formular e implementar iniciativas emprendedoras desde el MITRAB, que mejoren las condiciones de vida de los/las jóvenes.

Potenciar las capacidades, habilidades y destrezas de 22 jóvenes entre 16 y 24 años de edad, habitantes del municipio de San Francisco Libre, por medio del desarrollo de la captación de la experiencia que poseen los productores y las productoras locales, para posteriormente formular e implementar iniciativas emprendedoras desde el MITRAB.

Contribuir a la generación de empleos productivos y decentes en varios departamentos del país, mediante el diseño, la instalación, la puesta en marcha y el fortalecimiento de iniciativas emprendedoras sostenibles en el tiempo.

Proveer a madres de niños y niñas ex trabajadores/as de la actividad de picar piedras, de equipos y herramientas de seguridad ocupacional, en áreas de mejorar su productividad y desarrollo ocupacional, dentro del marco del Plan de Erradicación del Trabajo Infantil. 


\begin{tabular}{|l|l|}
\hline \multicolumn{1}{|c|}{ Programa o Política } & \multicolumn{1}{c|}{ Objetivo } \\
\hline $\begin{array}{l}\text { Forjando Juventud } \\
\text { Emprendedora }\end{array}$ & $\begin{array}{l}\text { Capacitación, elaboración e implementación de planes de negocios que propi- } \\
\text { cien la incubación y creación de MIPYMES que, a su vez, serán las que garantiza- } \\
\text { rán el empleo a sus propietarios/as (autoempleo) y, por ende, la contratación y } \\
\text { generación de nuevos empleos, contribuyendo de esta forma a la inclusión social } \\
\text { de la juventud nicaragüense. }\end{array}$ \\
\hline PAE Emprendedores & $\begin{array}{l}\text { Contribuir al desarrollo económico del país a través de la capacitación, elabo- } \\
\text { ración e implementación de planes de negocios que propicien la incubación y } \\
\text { creación de MIPYMES. }\end{array}$ \\
\hline $\begin{array}{l}\text { Proyecto Autoempleo } \\
\text { PAE-MUJER Emprendedoras }\end{array}$ & $\begin{array}{l}\text { Contribuir al desarrollo económico en Matagalpa, por medio de la implementa- } \\
\text { ción de políticas activas de empleo con talleres de capacitación dirigidos a mu- } \\
\text { jeres para la elaboración e implementación de ideas emprendedoras variables y } \\
\text { factibles }\end{array}$ \\
\hline $\begin{array}{l}\text { Proyecto de autoempleo } \\
\text { dirigido a las familias }\end{array}$ & $\begin{array}{l}\text { Mejora de las capacidades y condiciones de trabajo de las familias en condiciones } \\
\text { socioeconómicas desfavorables, de territorios donde hay mayor incidencia de } \\
\text { trabajo infantil. }\end{array}$ \\
\hline
\end{tabular}

A diez años después de haber asumido el gobierno el FSLN, no hay duda de que la ESS ha tenido una importante expansión. Desde el 2007 se han puesto en marcha numerosas políticas, programas de desarrollo nacional y reformas institucionales que tienen como objetivo promover la ESS. En un contexto mundial complejo en el que cada vez más gobiernos dan señales en su intención de fortalecer el apoyo a las organizaciones y empresas de la ESS, Nicaragua es un caso muy útil para un análisis que examine los desafíos de forjar un entorno de políticas más habilitadas para la ESS.

Pero como en todo país, nunca es fácil hacer realidad los objetivos de las políticas y las reformas institucionales y siempre salen algunas limitaciones en las cuales se pudiera mejorar, en el país una de las organizaciones entre varias que resaltan limitantes es el Movimiento Autónomo de Mujeres (MAM). El MAM, identifica como limitantes, la dificultad para acceder a información; hermetismo con que se manejan los asuntos públicos desde el gobierno y que las mujeres tienen mayor acceso a cargos de poder en términos formales, pero no de manera sustantiva.

En general, son buenas y excelentes iniciativas desde el gobierno y que favorecen la ESS; sin embargo, se cree que sería mucho mejor si se consideran los siguientes aportes: ampliar la capacidad y cobertura institucional; mejorar el grado de coherencia entre las políticas-planes-programas-proyectos, mejorar la participación de los principales actores para cada programa, disminuir las brechas de que si las políticas son de Gobierno o Partido o de Nación esto afecta la sostenibilidad de los procesos, que tan probables es que las buenas experiencias innovadoras lleguen a ser institucionalizadas y por último considerar no pensar por uno sino escuchar las voces en cada pueblo por ejemplo los Pueblos Indígenas también cuentan con su propia Economía Indígena. 


\section{Experiencia para ilustrar los procesos de empoderamiento, participación e inclusión social y económica}

A continuación, presento tres experiencias de procesos realizados que apuestan por la Economía Social Solidaria (ESS), una experiencia que realiza la universidad URACCAN y dos desde el Gobierno Central.

\section{Caso 1: La experiencia de URACCAN “Las Mujeres en la economía comunitaria indígena”}

Los procesos de acompañamiento comunitario que la URACCAN implementa en Economía Comunitaria con especial atención a las mujeres mestizas, indígenas y afrodescendientes. En las comunidades, la mujer es base de la organización social, porque transmiten a sus hijos e hijas los saberes de sus culturas. Los saberes son la base material del desarrollo, dado que las relaciones de género desiguales han obligado a las mujeres indígenas a conocer y dominar su medio, recursos y materias primas. Son ellas las que generan los saberes. La generación de conocimiento ha cambiado, las economías locales están siendo manejadas por las mujeres con formas apropiadas de producción para asegurar el manejo sostenible de los recursos. Esto se aprecia en la agricultura, pesca, semillas y plantas medicinales. Esta es la razón por la que deben ligarse los saberes a la economía.

En la Economía Comunitaria Indígena, el trabajo de la mujer tiene implicaciones diversas a niveles individuales y colectivos, por ser ellas las portadoras de los saberes de sus pueblos. Entre algunos aportes de las mujeres se pueden mencionar actividades: Agrícolas en la siembra, cosecha, cuido; artesanales como los tejidos, hornos, adornos; culturales en la recolección de frutas, cuido y protección de semillas; reproductivas como el cuido de ganado, pesca y acopio; reproducción social como los intercambios como el pana pana, mano vuelta, biribiri y fiestas comunitarias; reproducción cultural mediante la transmisión del idioma, preparación de suelos y tipos de siembra, preparación-conservación de alimentos tradicionales, saberes sobre usos ceremoniales y uso doméstico y valores para mantener, ajustar y reproducir formas de vida tradicionales y aportes a los servicios ambientales colectivos en las comunidades a través de la definición de normas de uso de suelo y de los recursos, conservación de semillas tradicionales y medicinales tradicionales, entre otras.

En los bosques la filosofía de los pueblos está basado en cuatro principios; Origen, los pueblos basan sus orígenes en la naturaleza del territorio donde habitan, por lo cual se preocupan de mantener sus bosques y ríos; Respeto a los dioses los pueblos tienen sitios sagrados donde moran los espíritus de sus ancestros, por tanto, al hacer uso de los recursos naturales tratan de no perturbarlos; equilibrio, si hacen uso del bosque para actividades agrícolas esas áreas las usan por 3 a 5 años seguidos, luego se dejan descansar entre 8 a 10 años permitiendo la sucesión secundaria del bosque; Patrimonio Natural, están consiente de que del bosque provienen todos los recursos 
para su sobrevivencia y la de futuras generaciones, por tanto, hay que concientizar a las nuevas generaciones sobre la necesidad de preservar el medioambiente; $y$ reciprocidad que en los pueblos de la Costa Caribe lo llaman Pana Pana o Biri-Briri y se expresa básicamente en el principio -si yo tengo, todos tenemos-. O sea que el emprendimiento de las mujeres indígenas tiene como eje central la colectividad y como objetivo, el bien común.

Caso 2: Desde el Gobierno "El Cooperativismo": En Nicaragua existen más cooperativas que en cualquier otro país de Centroamérica. Miles de cooperativas agrícolas y productivas en el país están haciendo un trabajo de hormigas, cambiando la economía de Nicaragua y estableciendo un nuevo modelo económico de largo plazo - la "economía social"-, compuesta por el movimiento asociativo de los pequeños y medianos productores, de los cuales las cooperativas y las asociaciones por rubro son el sector más avanzado y más numeroso, y que se encuentra en un proceso de asociatividad en diferentes modalidades. Las asociaciones de pequeños productores y las cooperativas producen, comercializan y consumen la gran parte de la producción alimentaria nacional (maíz, frijol, sorgo, arroz de secano, frutas, verduras). Actualmente existen registradas 5 , ooo cooperativas que agrupan a 389 , ooo socios y socias ( $44 \%$ ) en todas las ramas de la economía, como leche, carne, granos, hortaliza, transporte vivienda, turismo, ahorro crédito, entre otros. (INFOCOOP, 2015).

Caso 3: Hambre Cero: el bono productivo alimentario: tiene el doble propósito de promover la seguridad alimentaria y de empoderar a mujeres que viven en zonas rurales y periurbanas al capitalizar sus parcelas por medio del llamado bono productivo alimentario (BPA), así como por la vía de la capacitación y organización. El BPA que se otorga a las familias, y que representa el componente principal del programa, varía de acuerdo a las capacidades de cada familia, así como de las condiciones físicas, climáticas, de cada región. Los distintos bonos son para: (i) Familias rurales con extensiones de tierra de 1 a $10 \mathrm{Mz}$, el cual tiene como bien principal la vaca; (ii) Familias con un área menor a una $\mathrm{Mz}$, compuesto por aves, alimento para aves, material vegetativo y herramientas; (iii) Familias de áreas urbanas con patios grandes de al menos un cuarto de $\mathrm{Mz}$, que incluye un cerdo pequeño, aves, alimento para aves y cerdos y material de construcción. Sin embargo, el programa no plantea qué pasa cuando las mujeres no tienen tierra, ya que no contempla un componente de adquisiciones de tierras para ellas.

Para finales del año 2015 casi 150 mil mujeres habían recibido alguna variante del paquete de animales de corral e insumos. En el 2012, la responsabilidad de coordinar el programa fue transferida del Ministerio de Agricultura al recién creado Ministerio de Economía Familiar, Cooperativa, Comunitaria y Asociativa (MEFCA). Las mujeres están organizadas en grupos para recibir la capacitación, funcionamiento de los comités de coordinación, gestión de fondos rotatorios y el empoderamiento de las 
mujeres. En el 2013, habían Un mil 681 grupos de mujeres organizadas con hasta 50 miembros cada uno.

En fin, el programa tiene muchos aciertos, pero también desaciertos principalmente cuando se trata de su implementación en Pueblos Indígenas. En general, los principales desafíos que enfrenta el programa están: capacidad limitada del Estado de proveer un apoyo técnico y organizativo efectivo y a gran escala, la búsqueda del equilibrio entre la urgencia de extender el programa para abarcar a más mujeres, la calidad de los activos que se proveen y distribuyen, así como la cantidad de animales que mueren o son robados, disminuir el sesgo político al momento de la selección de beneficiarias, inclusión de beneficiarias que no clasifican como parte del grupo objetivo, limitada información sobre el programa, falta de rendición de cuenta por parte de los funcionarios del programa y el deficiente monitoreo y evaluación de impacto por parte del Gobierno (Chamorro y Utting, 2015). Sumado a esto la multiculturalidad de la nación exige modelos, enfoques y métodos para contexto diferentes, es así que en territorios de Pueblos Indígenas se sabe que los inconvenientes han sido: entrega del bono en lugares cerca de la carretera muy distantes de las comunidades de destinos, entrega de material vegetativos que ya cuentan en las comunidades lo que provoca que el material se quede en el camino, material vegetativo y animal de poca calidad, entrega de material vegetativo que requieren de alimentación e insumos procesados ausentes en la comunidad y la falta de asistencia técnica en cobertura y pertinencia cultural, una ventaja para las mujeres indígenas es que no se les solicita ningún documento referido a la tierra por ser colectivas, este es un arreglo que se hace con los Gobiernos Territoriales Indígenas.

A pesar de estas limitantes la mayoría de los estudios también dejan ver el impacto general positivo en lo referente a la producción de alimentos y su consumo, así como ciertos aspectos del empoderamiento de las mujeres. Un estudio de las Naciones Unidas destacó una serie de impactos que citamos a continuación:

"Durante los tres años que tiene el programa, ha aumentado la ingesta diaria de alimentos, la asistencia de los niños/as a la escuela está garantizada, los ingresos son más estables, las mujeres beneficiarias están más organizadas, ha aumentado la participación comunitaria y se han fortalecido las calidades de liderazgo" (Chamorro et al, citando a Cáceres).

Otro estudio realizado por el Instituto para Estudios Estratégicos y Políticas Públicas (IEEPP) nota lo siguiente:

"El Programa... representa un avance en los programas pro-pobre desarrollados en el país al incorporar el aspecto productivo agropecuario, que prioriza en cobertura a mujeres y comunidades indígenas...Debe valorarse positivamente el hecho de que se promueva el desarrollo económico y el empoderamiento de las mujeres, así como 
la incorporación de una discriminación positiva hacia las comunidades étnicas. ". (IEEPP, 2011).

Otro estudio realizado por el Grupo Venancia en el 2015 expresa la siguiente valoración:

“....se ha obtenido un alto progreso en la producción de alimentos, generación de empleo y un mayor poder de negociación en el hogar por parte de las mujeres, pero también había serios problemas ocasionados por el declive de la asistencia técnica, cooperativas a nivel primario que eran funcionales y un persistente clientelismo". (IEEPP, 2011).

Pero aparte de los aspectos técnicos y políticos-administrativos; qué tan transformativo ha sido el programa. Diversas opiniones realizadas a algunos actores coinciden en que el empoderamiento de las mujeres participantes es limitado por factores y relaciones culturales y sociales asociadas con el machismo ylos papeles e identidades de las mujeres como "amas de casa" en vez de "productoras: su falta de control sobre los presupuestos familiares; y su limitado papel de lideresas en las comunidades. A lo mejor sería conveniente diseñar un plan de capacitación más allá de los aspectos técnicos, sino que se aborden temas de liderazgo femenino, género, interculturalidad, economía indígena.

Por otro lado, en la dimensión de acción colectiva asociada a las organizaciones de mujeres siguen subdesarrolladas. No existen claros mecanismos de comunicación, articulación y complementariedad tanto a nivel horizontal como a nivel vertical y esto se profundiza aún más en organizaciones de mujeres indígenas y por último el concepto amplio de mejoramiento de vida y del Buen Vivir de los Pueblos abarcan múltiples dimensiones que entre todas contribuyen al bienestar de las familias, comunidades, territorios y pueblos.

Los beneficios que emana el programa Hambre Cero son reales, pero no se debe exagerar su contribución al bienestar de los hogares, puesto que constituye solo una parte de las distintas dimensiones del bienestar de los hogares.

Retos en el país para potenciar el aporte de la Economía Social Solidaria desde las economías comunitarias: populares, campesinas, indígenas, afrodescendientes y étnicas

1. A pesar de muchas iniciativas sobre Economía Social Solidaria hay que avanzar en la construcción de marcos teóricos y conceptuales lo cual es inconcluso.

2. Diseñar concretamente políticas y diseño de instrumentos metodológicos para su fomento e implementación, así como la articulación y complementariedad entre ellas para la ESS. 


\section{CIENCIAS SOCIALES}

3. La disgregación y atomización que caracteriza las experiencias de economía solidaria en los territorios; o sea que la articulación y complementariedad es una necesidad por construir.

4. A pesar de la diversidad de expresiones locales y culturales en el país, es muy crítico aún el uso de referencias únicas para estos procesos a nivel semi urbano y urbano.

5. A pesar de los resultados bastantes favorables, positivos de estos programas para fomentar, profundizar y mejorar su implementación orientado a la Economía Social Solidaria, queda la incertidumbre de que tan sostenible sería esta experiencia. ¿Puede sobrevivir programas como Hambre Cero en el caso de que llegue al poder otro partido diferente al FSLN? ¿Qué tan seguro sería el financiamiento para este tipo de políticas y programas?

6. El mayor desafío en las instituciones es transversalizar los principios y valores de la Economía Comunitaria Intercultural en todo su quehacer y prácticas cotidianas al interior y exterior. Así como de las alianzas, redes y vínculos

7. La presencia de 22 pueblos indígenas en el pacífico, centro y norte del país, así como de seis grupos étnicos con identidades propias en la Costa Caribe, debe mejorarse la implementación de estos programas con perspectiva intercultural de género, teniendo como base la Economía Comunitaria.

8. Sabiendo que este es un tema nuevo, complejo y con poca información, es un reto el diseño del modelo para que "otra economía sea posible”, en nuestro país.

\section{Conclusiones}

A pesar de estos retos y otros no mencionados, Nicaragua cuenta con las condiciones propicias para desarrollar un entorno nacional favorable de la Economía Social Solidaria por (i) Contar con un amplio sector de pequeños productores agrícolas y trabajadores urbanos por cuenta propia; (ii) Un alto grado de organización; (iii) Un nivel adecuado de distribución y acceso a la tierra; (iv) Un nivel de conciencia que se requiere otro tipo de economía a la existente y (v) una riqueza cultural con saberes, conocimientos y prácticas de Economías Comunitarias Interculturales.

En general, si bien es cierto hay un marco jurídico favorable e instrumentos que facilitan la promoción de la Economía Social Solidaria en el país, todavía hace falta mejorar en algunos elementos como (i) Las coordinaciones interinstitucionales con la Sociedad Civil; (ii) Definición de marcos conceptuales, mecanismos e instrumentos claros para implementar el marco jurídico, planes, programas, proyectos, protocolos, normativas, seguimiento, coberturas adecuadas y modelos de desarrollo económicos, sociales, ambientales con pertinencia cultural, (iii) Avanzar en cambios de actitudes, percepciones y mentalidades de las y los funcionarios públicos y por último (iv) Dejar 
de pensar por los Pueblos Indígenas, Afrodescendientes y Comunidades Étnicas y Considerar aún más Economías propias como la Economía Comunitaria Intercultural.

La ESS, es necesaria, imprescindible e inevitable porque el sistema capitalista ya no puede proveer de más empleo y está en crisis generalizada. En este contexto, la ESS solamente es viable si, se considera a la Economía Comunitaria Intercultural como base, se mantiene la lucha a través de movimientos socioculturales, asegurar aliados en toda Latinoamérica. Recordar que es una lucha desde abajo, dura y a largo plazo.

Se sugiere profundizar aún más en este estudio sobre el marco conceptual, en los conocimientos, saberes y prácticas vivenciales de la Economía Comunitaria Intercultural que aporten a que "Otra economía sea posible" llámese Economía Social Solidaria u otro nombre, pero con la filosofía Comunitaria.

\section{Lista de referencias}

Álvarez Vijil, Ana Lucía. (2014). Políticas públicas que promueven el empoderamiento económico de las mujeres en Nicaragua. Managua FIDEG.

APRODIN. (2011). Revista Voces Indígenas. Revista informativa de la Red de Pueblos Indígenas del Pacífico, Centro y Norte de Nicaragua. Edición No. 1 abril - mayo 2011.

BCN. (2015). Nicaragua en cifras 2015.

BCN. (2016). Nicaragua en cifras 2016.

CELADE (2016). División de Población de la CEPAL.

Chamorro Amalia, Utting Peter (2015). Políticas públicas para la economía social y solidaria: hacia un entorno favorable. Centro Internacional de Formación (CIF) y Organización Internacional del Trabajo (OIT).

FIDEG. (2012). Encuesta de hogares para medir la pobreza.

Grupo Venancia. (2015). "Hambre Cero: ¿cómo les va a las mujeres? " Envió, No. 396, marzo

Hernández, R., Fernández, C., \& Baptista, M. (2010). Metodología de la investigación. México. McGra-Hill.

Hooker, B. (2017). Educación Superior, Pertinente y de Calidad: Inclusión, Diversidad, Derechos Humanos y Extensión Social: Experiencia de la Universidad Comunitaria Intercultural. 
Instituto de Estudios Estratégicos y Políticas Públicas (IEPP, 2011). Hambre Cero: Avances y Desafíos; Tercer Informe de Evaluación del Programa Productivo Agropecuario. Managua: IEPP.

SIMAS. (2011). Políticas Nacionales y su impacto sobre la capacidad de los Pequeños Productores Nicaragüense para tomar decisiones acertadas frente a los mercados globalizados. Red de Aprendizaje Pequeños Productores como Actores en los Mercados Globalizados. Servicio de Información Mesoamericano sobre Agricultura Sostenible (SIMAS).

UNICEF. (2009). Atlas Sociolingüístico de pueblos indígenas en América Latina.

URACCAN. (2015). Plan Estratégico Institucional 2015- 2019.

Zúniga-Morales, V. (2010). Evaluación Interna del Proyecto "Fortalecimiento de URACCAN Las Minas Fase IV.

Zúniga-Morales, V. (2013). Evaluación interna Participativa del Proyecto "Desarrollo de capacidades técnicas y humanas para la implementación del Plan de Desarrollo Regional con Identidad en el Territorio Las Minas." 